\title{
Effects of synbiotic supplementation on gut functioning and systemic inflammation of community-dwelling elders - secondary analyses from a randomized clinical trial
}

\author{
João VALENTINI NETO, Terezinha Perricci CHELLA, Danielle Panipucci RUDNIK and \\ Sandra Maria Lima RIBEIRO
}

Received: 30 August 2019

Accepted: 27 October 2019

\begin{abstract}
Background - Aging is a complex process marked by alterations on gut functioning and physiology, accompanied by an increase on the inflammatory status, leading to a scenario called "inflammaging". Objective - To evaluate the effects of a synbiotic substance on systemic inflammation, gut functioning of community-dwelling elders. Methods - This is a secondary analysis from a randomized clinical trial, lasting 24 weeks, including 49 elders, distributed into two groups: SYN (n=25), which received a synbiotic substance (Frutooligossacaride 6g, Lactobacillus paracasei LPC-31 $10^{9}$ to $10^{8} \mathrm{UFC}$, Lactobacillus rhamnosus HN001 $10^{9}$ to $10^{8} \mathrm{UFC}$, Lactobacillus acidophilus NCFM $10^{9}$ to $10^{8}$ UFC e Bifidobacterium lactis HNO19 $10^{9}$ to $10^{8} \mathrm{UFC}$ ), or PLA ( $\left.\mathrm{n}=24\right)$, receiving placebo. The evaluations consisted of serum IL-10 e TNF- $\alpha$ (after overnight fasting), evaluation of chronic constipation (by Rome III Criteria) and faeces types (by Bristol Stool Form Scale). Data were compared before and after the supplementation time, and between groups. Results - No significant differences were found between baseline and final values of serum inflammatory markers. Some subtle beneficial changes were observed in SYN, concerning both gut functioning and faeces types. Conclusion - From our data, synbiotic supplementation showed a subtle benefit in gut functioning in apparently healthy community-dwelling elders. Our findings can suggest that the benefits in healthy individuals were less expressive than the ones presented in studies with individuals previously diagnosed as dysbiosis. Future studies, comparing elders with and without gut dysbiosis can confirm our findings.
\end{abstract}

HEADINGS - Gastrointestinal tract. Gastrointestinal microbiome. Synbiotics. Aged.

\section{INTRODUCTION}

The aging process, together with physiological changes, have been related to important gastrointestinal disorders, due to a number of factors such as tooth loss, reduction in salivation, low physical activity, poor food intake polypharmacy and others ${ }^{(1)}$. Polypharmacy and decreased mobility may be responsible for most of the cases of constipation and diarrhoea referred by elders ${ }^{(2,3)}$. Constipation refers to a high effort required to and/or incomplete evacuation, hard faeces and diminished frequency of evacuation ${ }^{(4)}$. Diarrhoea, in turn, is defined as the abnormal increase on the evacuation frequency and/or watery faeces ${ }^{(2)}$. Besides the social and psychological burden associated to constipation and/or diarrhoea, these manifestations are also attached to consequences such as haemorrhoids, faecal impaction, faecal incontinence, rectal prolapse, alterations in tonus and decrease on perineum function ${ }^{(2,5)}$; these conditions affect the quality of life, compromising daily activities, performance, as well as the nutritional status ${ }^{(6)}$.

Gastrointestinal disorders in aging has been pointed to be associated to changes in gut microbiota. It has been observed a reduction in some beneficial bacteria populations, for instance,
Firmicutes and Bifidobacteria, combined to an increase on Bacteroidetes and Proteobacteria populations ${ }^{(7-9)}$. This imbalance can modify important functions of gut microbiota, such as bacterial fermentation, which in turn is fundamental to the production of derivatives such as short chain fatty acids (SCFA); these fatty acids act improving the gut barrier function, as well as promoting benefits to host metabolism and colonic motility ${ }^{(8)}$.

In adition to the age-related gastrintestinal disorders, aging is frequently associated to a subclinical inflammatory status, which some authors name as "inflammaging"(10). The exact origin of this status is not completely understood, but the intestine certainly is involved; the increase in gut permeability (due to the loss of barrier function) allows the movement of bacteria or bacterial fragments towards the systemic circulation, reaching specific receptors in different tissues, favouring the inflammatory condition ${ }^{(10,11)}$.

As such, different protocols aiming to improve gut microbiota, gut functionality and systemic inflammation have been proposed ${ }^{(12)}$. A direct relationship between diet and gut microbiota composition has been pointed by many authors ${ }^{(8)}$; the intake of some components, from diet or from supplementation, is capable of improving the bacterial fermentation in colon. In this context, some substances 
have been studied. For instance, probiotics are defined as live microorganisms, which when administered in adequate amounts confer a health benefit to the host; in turn, prebiotics are defined as nondigestible food ingredient that beneficially affects the host by selectively stimulating the growth and/or activity of one or a limited number of bacteria in the colon; finally, synbiotics are food or supplement product containing both probiotics and prebiotics ${ }^{(13)}$. The intake of these substances is supported by some findings indicating their ability to promote the selective stimulation of host gut microbiota and its activity, reducing the cellular atrophy, diminishing the gut permeability by the tight junction strengthening, and as final consequences, promoting improvements on gut function and inflammatory status ${ }^{(9,14-16)}$.

Symbiotic supplementation in elderly have been conducted in various scenarios: inflammatory markers ${ }^{(17)}$; intestinal polyamine concentrations $^{(18)}$; gut microbiota composition, metabolism, immunity and blood lipids levels ${ }^{(19)}$; infectious complications after gastrointestinal surgeries ${ }^{(20)}$; mental disorders and inflammation ${ }^{(21)}$.

One important point to be highlighted is that the use of pre, pro or synbiotic substances has shown benefits, especially in individuals who presented previous intestine-related health issues. The use of this type of substance by "apparently healthy" individuals is scarcely investigated in the literature, and at the same time, broadly recommended at clinical practice ${ }^{(22-24)}$. Considering the very frequent intake of medicines and supplements by elders, which can contribute to a picture of polypharmacy, one question needs to be answered: the intake of synbiotics by apparently healthy elders can really contributes with any benefit?

As such, the present study aimed to evaluate the effects of synbiotics supplementation on aspects of gut functionality and systemic inflammation in apparently healthy community-dwelling elders.

\section{METHODS}

This study derives from a broader randomized, parallel doubleblind controlled clinical trial (Brazilian Registration of Clinical Studies - REBEC; RBR-6qr9xx). We studied elderly individuals registered at a Basic Health Unit of São Paulo City, SP, Brazil. Individuals were informed about the study, and invited to take part in it, while in the waiting room of the unit. These procedures (invitation and information) were performed by the authors of the study. Individuals were required to be between 65 and 90 years, be of either gender and should fulfil the maximum of two criteria to be considered as pre-frail, according to Fried et al. ${ }^{(25)}$. The participants should not have experienced, during the previous six months, any chronic inflammatory or acute bowel disease or have taken any probiotic, prebiotic, synbiotic substance, or antibiotics, or laxative substances; they should not have had any type of cancer during the previous five years. The study started at July, 2013 and finished in March, 2014.

The sample size (25 participants per group) was calculated according to Cohen ${ }^{(26)}$, taking into account the variable with the highest variability (cytokines) and the dropout rates (12\%), obtained from a previous pilot study ${ }^{(27)}$; the power of the statistical analysis $(90 \%)$; the size of the effect (0.75); and the level of significance $(5 \%)$.

The participants were randomly allocated into two groups: SYN [synbiotic $(n=25)]$ that consumed two daily doses of a synbiotic substance (Frutooligossacaride 6g, Lactobacillus paracasei LCP-31 $10^{9}$ to $10^{8}$ UFC, Lactobacillus rhamnosus $H N 00110^{9}$ to $10^{8} \mathrm{UFC}$, Lactobacillus acidophilus NCFM $10^{9}$ to $10^{8}$ UFC and Bifidobac- terium lactis HN019 $10^{9}$ to $10^{8}$ UFC); or PLA [placebo $\left.(n=24)\right]$, who consumed maltodextrin $(6 \mathrm{~g})$ following the some instructions of SYN group. Supplementation lasted 24 weeks. FIGURE 1 describes the flow diagram of the study, from the recruitment until the final evaluation.

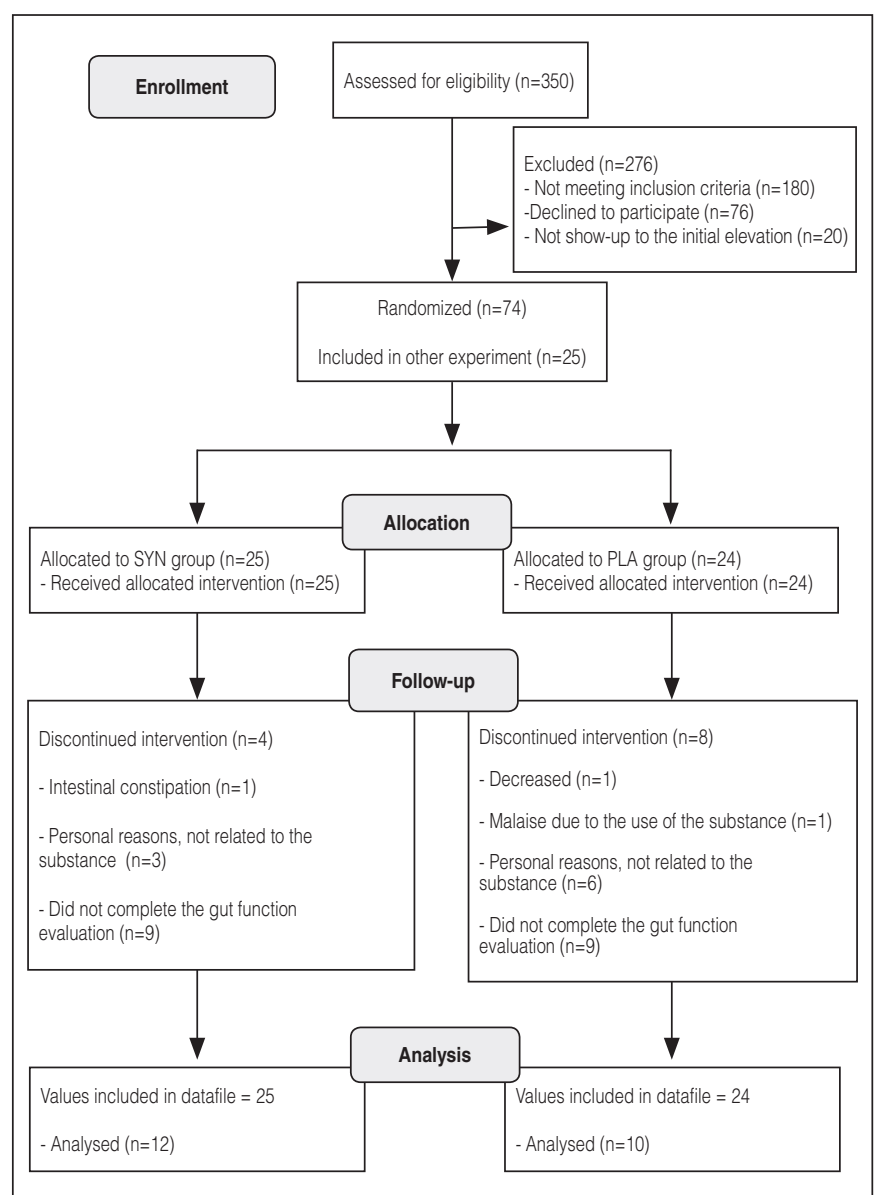

FIGURE 1. Flow diagram of the study based on CONSORT 2010.

As previously described ${ }^{(21)}$ the randomization was performed by a person not related to the study and was made in blocks. After the allocation of the participants, they were advised to follow the same instructions: to take daily one dose at morning and the other dose at night. Once a month all the participants received the supplements in white and opaque envelops, free of the corresponding substance information, inside a box containing only the participant's number. The participants were requested to return the last empty box and envelops every time they received a new one.

During the protocol time, the participants received weekly phone calls, where they were questioned about possible difficulties to take the supplements, any side effects, and other issues.

\section{Initial and final evaluations \\ - General information questionnaire}

During the initial evaluation, the participants answered some questions regarding their demographic and health status. In addition, each filled out a supplementation diary throughout the study, where they described any side-effects noted and the time of intake of the supplement. 


\section{- Blood withdrawn and analysis of biological markers}

The blood was collected after 8-12 h fasting, and then centrifuged and stored for further analysis of interleukin-10 (IL-10) and tumour necrosis factor- alfa (TNF- $\alpha)$. Both molecules were analyzed using the Milliplex MAP=Multiple Analyte Profiling method (HCYTMAG-60K-03; Millipore ${ }^{\circledR}$; Luminex $^{\circledR}$ xMAP $^{\circledR}$ technology, immunoassays on the surface of fluorescent-coded magnetic beads). Initially, the plate was washed with a buffer and each Standard or Control were then added to the wells, followed by Assay Buffer and matrix solution. Plasma samples were added to wells, followed by Mixed Beads. The plate was sealed, wrapped in foil, and placed on a plate shaker overnight. After washing the plate twice, detection antibody was added to each well, followed by incubation with agitation at room temperature. StreptavidinPhycoerythrin was then added to each well, shaking at room temperature, and washing twice. Following the addition of sheath fluid to all wells, the beads were then resuspended on a plate shaker. The plate was run on a Luminex $200^{\mathrm{TM}}$, with xPONENT software. From the Median Fluorescent Intensity (MFI), the cytokine concentrations were calculated using a 5-parameter logistic or spline curve-fitting method., both by MAP=Multiple Analyte Profiling method (HCYTMAG-60K-03; Millipore ${ }^{\circledR}$ ).

\section{- Gut functionality}

Chronic constipation was evaluated by the Rome III Criteria ${ }^{(28)}$, which consisted of six items, to be answered as yes or no, taking into account the last six months: Q1 = Straining during at least $25 \%$ of defecations; Q2= Lumpy or hard stools in at least $25 \%$ of defecations; Q3 = Sensation of incomplete evacuation for at least $25 \%$ of defecations; Q4= Sensation of anorectal obstruction/blockage for at least 25\% of defecations; Q5= Manuals maneuvers to facilitate at least $25 \%$ of defecations; Q6 = Fewer than three defecations per week. We analyzed the answers one by one, comparing the times before and after the supplementation.

The types of faeces were investigated by the Bristol Stool Form Scale (BSFS), a visual tool which has the aim to evaluate, in visual representations, the form and consistency of stool (seven representations in total). The participant had to choose the figure which reprented the most their own faeces. The scale was translated, adapted and validated to the Brazilian portuguese ${ }^{(29)}$.

\section{Anthropometric measures}

All the participants were evaluated for height and weight to calculate the body mass index $\left(\mathrm{BMI}=\right.$ weight $/$ height $\left.^{2}\right)$.

\section{Ethical aspects}

The procedures and the aim of the study were explained to the participants. While all the subjects were informed of the importance of remaining in the study for the entire six months, they were reassured of their right to withdraw from the study at any time. All participants signed an informed consent form, and the project was approved by the Local Ethics in Human Research Committee (process 200.870/2013).

\section{Data analyses}

The analyses were conducted without imputed values for the missing data, due to the above of expected number of dropouts. The continuous variables were presented by mean and standard deviation; age and BMI were compared by t-student test. The inflammatory markers were compared by repeated measures ANOVA, with LSD-test as post-hoc, considering firstly the IL-10 levels, secondly considering only TNF- $\alpha$ levels, and thirdly considering the IL-10/ TNF- $\alpha$ ratio (which constituted anti/pro inflammatory balance). Gut functioning data (from Rome Criteria III questions and for the Bristol Scale classification) were analysed for Absolute Risk Reduction, with respective confidence intervals (95\%), and the stool classification was also analysed for proportion comparisons by Fisher exact test, considering "events" the cases when the participants, by the end of the study, showed improvement in comparison to the beginning. Data were analyzed using IMB SPSS Statistics $23^{\circledR}$, and Microsoft Excel $2013^{\circledR}$. Significant level was considered at 5\%.

\section{RESULTS}

After the evaluation of inclusion and exclusion criteria, fortynine voluntaries were randomized to one of the groups (FIGURE 1). The PLA group was composed by five men and 19 women with mean age of $77.60 \pm 7.22$ years, and SYN group had five men and 20 women with mean age of $75.33 \pm 6.85$ years. As depicted at TABLE 1, there were no significant differences in BMI and age when the groups were compared at the baseline, allowing us to conclude that the groups were similar at the beginning of the experiment.

At the end of the experimental period, the sample was composed by 22 participants; 10 in the PLA group and 12 in SYN group (FIGURE 1). The dropout rate was, therefore, higher than assumed for the sample size calculation, which reduced our statistical power to $70 \%$, instead of the initially planned $(90 \%)$.

FIGURE 2 shows the number of affirmative answers for each question of the Rome III Criteria and the answers corresponding

TABLE 1. Baseline feature of the sample, and comparison between PLA and SYN groups. São Paulo (SP), 2014.

\begin{tabular}{lccccc} 
& & Age & & BMI \\
& SYN & PLA & SYN & PLA \\
& mean \pm SD & mean \pm SD & P-value & mean \pm SD & mean \pm SD \\
\hline Women & $77.33 \pm 6.51$ & $78.71 \pm 5.05$ & & $28.25 \pm 5.61$ & $25.08 \pm 5.61$ \\
Men & $69.33 \pm 4.04$ & $75.00 \pm 12.00$ & $21.90 \pm 2.02$ & $26.86 \pm 1.89$ \\
Total & $75.33 \pm 6.85$ & $77.60 \pm 7.22$ & 0.4573 & $26.66 \pm 5.65$ & $25.62 \pm 2.68$ \\
\hline
\end{tabular}

*Significant level $(P<0.05)$ 


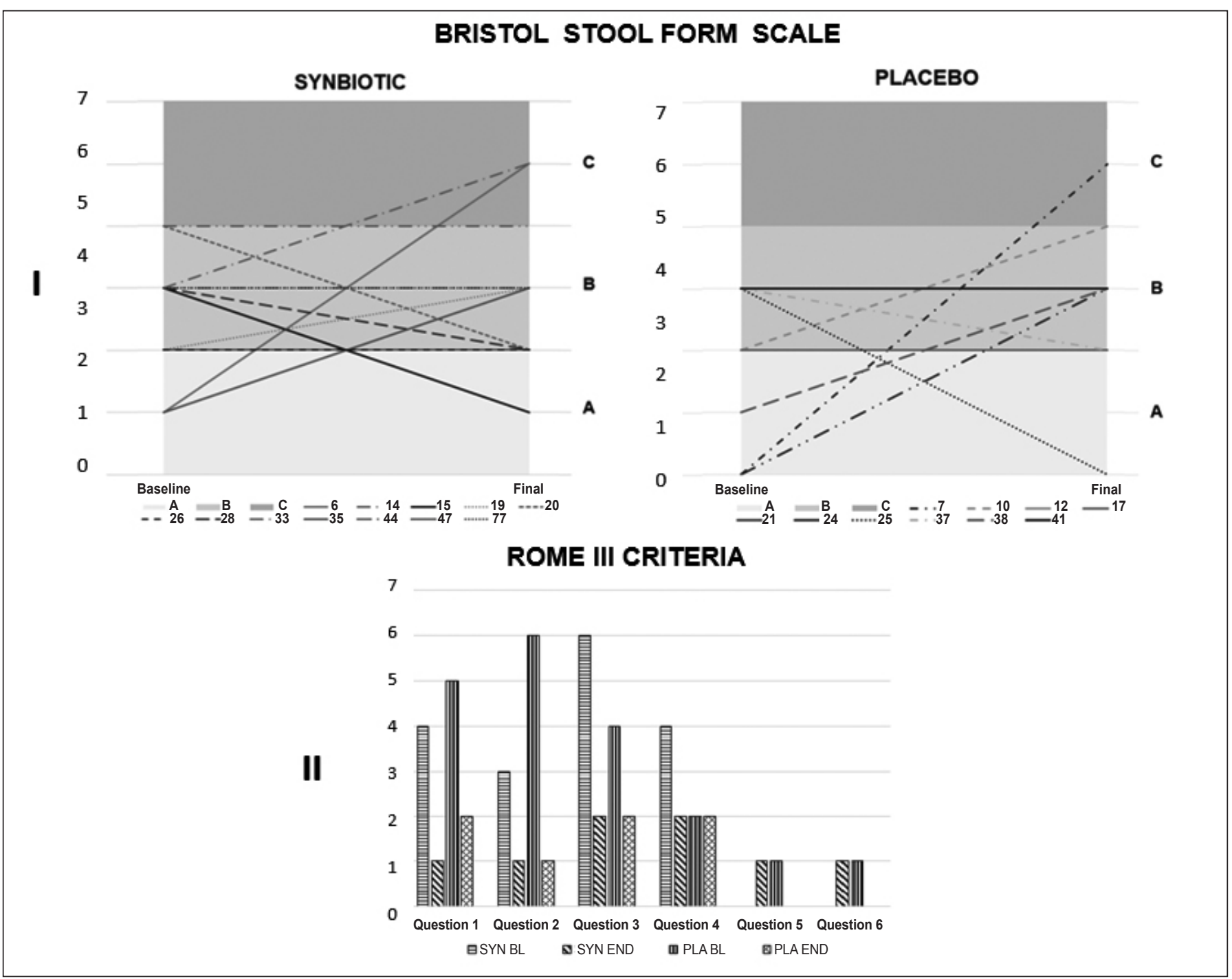

FIGURE 2. Baseline and final answers for the Bristol Stool Form Scale (I) and for the ROME III Criteria (II) by group SYN and PLA. São Paulo (SP), 2014. Question 1= Straining during at least 25\% of defecations. Question 2= Lumpy or hard stools in at least 25\% of defecations. Question 3= Sensation of incomplete evacuation for at least $25 \%$ of defecations. Question 4= Sensation of anorectal obstruction/blockage for at least 25\% of defecations. Question $5=$ Manuals maneuvers to facilitate at least 25\% of defecations. Question 6= Fewer than three defecations per week. Types = Types of evacuation form according to the Bristol $(\mathrm{A}=$ constipated; $\mathrm{B}=$ regular; $\mathrm{C}=\mathrm{diar}$ hea $)$. Some individuals are overlapped due to the same route from the start to the end of the experiment.

to each type of evacuation of BSFS, grouped in three categories: $\mathrm{A}=$ constipated $(1$ and 2$), \mathrm{B}=$ regular $(3,4$ and 5$)$ and $\mathrm{C}=$ diar rhea (6 and 7).

TABLE 2 depicts the Absolut Risk Reduce analysis for the Rome III and BSFS. Most of the parameters investigated (six questions of Rome III and BSFS type) showed that improvements in SYN group were significant, when confronted to PLA group.

The results of the inflammatory cytokines analysis are shown in TABLE 3. There was not significant difference between the interaction time vs group in any of the biomarkers.

\section{DISCUSSION}

This study aimed to investigate the effects of six months intake of a synbiotic substance on gut functionality and inflammatory markers of apparently healthy community-dwelling elderly. In general terms, we found benefits on gut function and on tools consistency with the intake of SYN; however, the inflammatory markers did not show any significant difference.

The benefits of pro, pre or synbiotic supplementation are known as beneficial to gut functionality. Studies similar to ours, in any way, have shown that probiotic intake (which are related to synbiotic) is capable of improving constipation in general population; the benefits pointed by the studies included increasing in the colonic transit ${ }^{(30)}$; improvement in evacuation frequency ${ }^{(31)}$; improvement in stool consistency ${ }^{(32)}$, among others. The benefits of these substances seem to be more pronounced when planned to specific groups, such as the ones diagnosed as functional constipation ${ }^{(33)}$. Waitzberg et al. ${ }^{(34)}$ found in a placebo-controlled study an improvement in evacuation parameter and the intensity of constipation in constipated 
TABLE 2. Improvement, from the initial to the final data, of the parameters related to gut functionality. São Paulo (SP), 2014.

\begin{tabular}{|c|c|c|c|c|c|c|c|}
\hline \multirow[b]{3}{*}{ Q1 } & \multicolumn{2}{|c|}{ SYN } & \multicolumn{2}{|c|}{ PLA } & \multirow[b]{2}{*}{ ARR } & \multirow{2}{*}{\multicolumn{2}{|c|}{$95 \% \mathrm{CI}$}} \\
\hline & $\mathbf{N}^{\circ}$ events & Total & $\mathrm{N}^{\circ}$ events & Total & & & \\
\hline & 11 & 12 & 8 & 10 & -0.1167 & -0.4340 & $0.1895 *$ \\
\hline Q2 & 11 & 12 & 10 & 10 & 0.0833 & -0.2025 & $0.3539 *$ \\
\hline Q4 & 11 & 12 & 9 & 10 & -0.1167 & -0.3284 & $0.2661 *$ \\
\hline Q5 & 11 & 12 & 10 & 10 & 0.0833 & -0.2025 & $0.3539 *$ \\
\hline Q6 & 11 & 12 & 10 & 10 & 0.0833 & -0.2025 & $0.3539 *$ \\
\hline
\end{tabular}

ARR: Absolute Risk Reduction, for Rome III Criteria and Bristol Stool Form Scale; BSFS: Bristol Stool Form Scale; Q1: straining during at least 25\% of defecations; Q2: lumpy or hard stools in at least 25\% of defecations; Q3: sensation of incomplete evacuation for at least 25\% of defecations; Q4: sensation of anorectal obstruction/blockage for at least 25\% of defecations; Q5: manuals maneuvers to facilitate at least $25 \%$ of defecations; Q6: fewer than 3 defecations per week. *Statistical significance.

TABLE 3. Descriptive analysis of baseline and final data of inflammatory cytokines, and comparative analysis. São Paulo (SP), 2014.

\begin{tabular}{|c|c|c|c|c|c|c|}
\hline \multirow{2}{*}{ Citokynes } & \multirow{2}{*}{ Groups } & \multirow{2}{*}{$\begin{array}{c}\text { Baseline } \\
\text { Mean } \pm \text { SD }\end{array}$} & \multirow{2}{*}{$\begin{array}{c}\text { Final } \\
\text { Mean } \pm \text { SD }\end{array}$} & \multicolumn{3}{|c|}{$\begin{array}{c}P \text {-value } \\
\text { ANOVA* }\end{array}$} \\
\hline & & & & Time & $\begin{array}{r}\text { AN } \\
\text { Group }\end{array}$ & Interaction (time ${ }^{* *}$ group) \\
\hline IL-10 & SYN & $2.46 \pm 1.36$ & $2.11 \pm 0.98$ & 0.525 & 0.562 & 0.780 \\
\hline \multirow{2}{*}{ TNF- $\alpha$} & SYN & $10.06 \pm 4.54 *$ & $14.35 \pm 4.91 *$ & \multirow{2}{*}{$<0.001$} & \multirow{2}{*}{0.418} & \multirow{2}{*}{0.365} \\
\hline & PLA & $9.48 \pm 3.21 *$ & $15.14 \pm 5.60 *$ & & & \\
\hline
\end{tabular}

*Repeated measures ANOVA. **Differences on the same group, between different times (baseline and final).

women after the consumption of a synbiotic substance. It is important to point out that the study included only three participants over 65 years. Our study was developed with apparently healthy elders, which could explain our subtle results.

Improvement in evacuation frequency was observed by Granata et al. ${ }^{(35)}$ in free-living women above 82 years old, that consumed a mixture of yogurt containing probiotic bacteria and fructooligosaccharides for four weeks. Considering the effects of aging on gut function and evacuation type and frequency, it can be expected that the oldest individuals are more prone to have gut issues ${ }^{(36)}$; therefore, the age of the participants of Granata's study can explain the more beneficial results.

The absence of significant differences in our biomarkers of inflammation reflects the divergence existing in the literature. Some studies reported reduction in the pro-inflammatory cytokine's levels ${ }^{(17,19,37,38)}$ and increase on the anti-inflammatory ones ${ }^{(39)}$; others reported increase on pro-inflammatory levels ${ }^{(17)}$ after synbiotic comsumption. On other hand, studies performed with obese individuals, or in patients with liver steatosis ${ }^{(40)}$, showed more expressive improvements of inflammatory status ${ }^{(41)}$. Our sample, as apparently healthy, did not present chronic inflammatory conditions, and therefore, the supplementation of synbiotics is assumed to be unnecessary.

It is important to highlight some limitations of our study. The dropout rate was above of the initially estimated, and due to this, our statistical power was reduced. However, among the reasons to abandon the study, only one participant who referred rejection to the supplement was allocated at SYN group. In fact, the majority of the dropouts related to the substance were allocated in PLA group. Therefore, despite of the reduced number of participants at the end, we can assume subtle benefits related to the use of synbiotics. As a strength of our study, as far as we know, clinical studies supplementing synbiotics in apparently healthy community-dwelling elders, are still rare.

\section{CONCLUSION}

From our data, synbiotic supplementation showed a subtle benefit in gut functioning in apparently healthy community-dwelling elders. Our findings can suggest that the benefits in healthy individuals were less expressive than the ones presented in studies with individuals previously diagnosed as dysbiosis. Future studies, comparing elders with and without gut dysbiosis can confirm our findings.

\section{ACKNOWLEDGEMETS}

The authors express their gratitude to the students who helped in the data collection and organization of the data: Angelica MP Freitas, Jéssica G Bento, Eliana R Louzada, and Bruna S Gusmão.

The authors thank the São Paulo Research Foundation (FAPESP) for the grant support and schoolarships (process number 2012/15976-0). The authors also thank to Invictus Farmanutrição Ltda., Brazil ${ }^{\circ}$. JVN had his scholarship from Brazilian Higher Education Personnel Improvement Coordination (CAPES). 


\section{Authors' contribution}

Valentini Neto J: conceptualization, data curation, formal analysis, investigaton, methodology and writing-original draft. Chella TP, Rudnik DP: data curation, formal analysis, investigatio $\mathrm{n}$ a n d methodology. Ribeiro SML: conceptualization, funding acquisition, methodology, project administration, and review of the manuscript.

\section{Orcid}

João Valentini Neto. Orcid: 0000-0002-2280-4769.

Terezinha Perricci Chella. Orcid: 0000-0001-9111-8095.

Danielle Panipucci Rudnik. Orcid: 0000-0003-1432-4121.

Sandra Maria Lima Ribeiro. Orcid: 0000-0003-3150-516X.

Valentini Neto J, Chella TP, Rudnik DP, Ribeiro SML. Efeitos da suplementação com simbióticos sobre a função intestinal e a inflamação sistêmica de idosos inseridos na comunidade - análises secundárias de um estudo clínico-randomizado. Arq Gastroenterol. 2020;57(1):24-30.

RESUMO - Contexto - O envelhecimento é um processo complexo marcado por alterações no funcionamento e fisiologia intestinais, acompanhado de alterações no estado inflamatório, o que leva ao quadro denominado inflammaging. Objetivo - Avaliar os efeitos de uma substância simbiótica sobre o funcionamento intestinal e a inflamação sistêmica de idosos inseridos na comunidade. Métodos - Trata-se de uma análise secundária de um estudo clínico randomizado, com 24 meses de duração, que incluiu 49 idosos, distribuídos em dois grupos: SIM (n=25), que receberam uma substância simbiótica (Frutooligossacaride 6g, Lactobacillus paracasei LPC-31 $10^{9}$ to $10^{8} \mathrm{UFC}$, Lactobacillus rhamnosus HN001 $10^{9}$ to $10^{8}$ UFC, Lactobacillus acidophilus NCFM $10^{9}$ to $10^{8}$ UFC e Bifidobacterium lactis HNO19 $10^{9}$ to $10^{8}$ UFC), ou PLA (n=24), que receberam placebo. As avaliações foram realizadas antes e após o período de suplementação, e incluíram: concentrações de IL-10 e TNF- $\alpha$ no soro (após uma noite de jejum); investigação de constipação crônica (pelo Critério de Roma III) e dos tipos de fezes (pela Escala de Bristol). Os dados foram comparados entre antes e após a suplementação, e entre os grupos. Resultados - Não foram encontradas diferenças significativas entre valores iniciais e finais nos marcadores de inflamação; alguns benefícios sutis foram observados no grupo SIM, no funcionamento intestinal e nos tipos de fezes. Conclusão - A suplementação com simbióticos mostrou um benefício sutil nessa população. Nossos resultados apontam que idosos aparentemente saudáveis não se beneficiam tanto da suplementação de simbióticos quanto pessoas previamente identificadas com disbiose. Estudos futuros, comparando idosos com e sem disbiose poderão confirmar esses achados.

DESCRITORES - Trato gastrointestinal. Microbioma gastrointestinal. Simbióticos. Idoso.

\section{REFERENCES}

1. Dagli RJ, Sharma A. Polypharmacy: A Global Risk Factor for Elderly People. J Int Oral Health. 2014;6(6):i-ii.

2. Holt PR. Diarrhea and malabsorption in the elderly. Gastroenterol Clin North Am. 2001;30:427-44.

3. De Giorgio R, Ruggeri E, Stanghellini V, Eusebi LH, Bazzoli F, Chiarioni G. Chronic constipation in the elderly: a primer for the gastroenterologist. BMC Gastroenterol. 2015;15:130.

4. Prichard DO, Bharucha AE. Recent advances in understanding and managing chronic constipation. F1000Res. 2018;7

5. Costilla VC, Foxx-Orenstein AE. Constipation: understanding mechanisms and management. Clin Geriatr Med. 2014;30:107-15.

6. Schiller LR. Diarrhea and malabsorption in the elderly. Gastroenterol Clin North Am. 2009;38:481-502.

7. Tiihonen K, Ouwehand AC, Rautonen N. Human intestinal microbiota and healthy ageing. Ageing Res Rev. 2010;9:107-16.

8. Duncan SH, Flint HJ. Probiotics and prebiotics and health in ageing populations. Maturitas. 2013;75:44-50

9. Magrone T, Jirillo E. The interaction between gut microbiota and age-related changes in immune function and inflammation. Immun Ageing. 2013;10:31

10. Franceschi C, Bonafe M, Valensin S, Olivieri F, De Luca M, Ottaviani E, et al. Inflamm-aging. An evolutionary perspective on immunosenescence. Ann N Y Acad Sci. 2000;908:244-54

11. Franceschi C, Campisi J. Chronic inflammation (inflammaging) and its potential contribution to age-associated diseases. J Gerontol A Biol Sci Med Sci. 2014;69:S4-9.

12. Perez Martinez G, Bauerl C, Collado MC. Understanding gut microbiota in elderly's health will enable intervention through probiotics. Benef Microbes. 2014;5:235-46.

13. Douglas LC, Sanders ME. Probiotics and prebiotics in dietetics practice. J Am Diet Assoc. 2008;108:510-21.

14. Patel PJ, Singh SK, Panaich S, Cardozo L. The aging gut and the role of prebiotics, probiotics, and synbiotics: A review. BMC Geriatr. 2013;5:3-6.

15. Calder PC, Bosco N, Bourdet-Sicard R, Capuron L, Delzenne N, Dore J, et al. Health relevance of the modification of low grade inflammation in ageing (inflammageing) and the role of nutrition. Ageing Res Rev. 2017;40:95-119.

16. Martínez-Martínez MI, Calabuig-Tolsá R, Cauli O. The effect of probiotics as a treatment for constipation in elderly people: A systematic review. Arch Gerontol Geriatr. 2017;71:142-9.
17. Amati L, Marzulli G, Martulli M, Pugliese V, Caruso C, Candore G, et al. Administration of a synbiotic to free-living elderly and evaluation of serum cytokines. A pilot study. 2010;16:854-8.

18. Manzoni MSJ, Rossi EA, Pauly-Siqueira ND, Pinto RA, Roselino MN, Carlos IZ, et al. Consumption effect of a symbiotic beverage made from soy and yacon extracts containing Bifidobacterium animalis ssp. Lactis BB-12 on the intestinal polyamine concentrations in elderly individuals. Food Res Int. 2017;99(Pt1):495-500.

19. Costabile A, Bergillos-Meca T, Rasinkangas P, Korpela K, de Vos WM, Gibson GR. Effects of Soluble Corn Fiber Alone or in Synbiotic Combination with Lactobacillus rhamnosus GG and the Pilus-Deficient Derivative GG-PB12 on Fecal Microbiota, Metabolism, and Markers of Immune Function: A Randomized, Double-Blind, Placebo-Controlled, Crossover Study in Healthy Elderly (Saimes Study). Front Immunol. 2017;8:1443.

20. Okazaki M, Matsukuma S, Suto R, Miyazaki K, Hidaka M, Matsuo M, et al. Perioperative synbiotic therapy in elderly patients undergoing gastroenterological surgery: a prospective, randomized control trial. Nutrition. 2013;29:1224-1230.

21. Louzada ER, Ribeiro SML. Synbiotic supplementation, systemic inflammation, and symptoms of brain disorders in elders: A secondary study from a randomized clinical trial. Nutr Neurosci. 2018:23;1-8.

22. Doron S, Snydman DR. Risk and safety of probiotics. Clin Infect Dis. 2015;60:S129-S134.

23. Hamilton-Miller JM. Probiotic and prebiotics in the elderly. Postgrag Med J. 2004;80:447-51.

24. Walrand S. Dietary supplement intake among the elderly: hazards and benefits. Curr Opin Clin Nutr Metab Care. 2018;21:465-70.

25. Fried LP, Tangen CM, Walston J, Newman AB, Hirsch C, Gottdiener J, et al. Frailty in older adults: evidence for a phenotype. J Gerontol A Biol Sci Med Sci. 2001;56:M146-56.

26. Cohen J. Statistical power analysis for the behavioral sciences. 2nd ed. Hillsdale (NJ): Lawrence Erlbaum Associates 1988.

27. Neto JV, de Melo CM, Ribeiro SM. Effects of three-month intake of synbiotic on inflammation and body composition in the elderly: a pilot study. Nutrients. 2013;5:1276-86

28. Shih DQ, Kwan LY. All Roads Lead to Rome: Update on Rome III Criteria and New Treatment Options. Gastroenterol Rep. 2007;1:56-65.

29. Martinez AP, Azevedo GRd. Tradução, adaptação cultural e validação da Bristol Stool Form Scale para a população brasileira. Rev Latin-Am Enfermagem. 2012;20:583-9. 
30. Bazzocchi G, Giovannini T, Giussani C, Brigidi P, Turroni S. Effect of a new synbiotic supplement on symptoms, stool consistency, intestinal transit time and gut microbiota in patients with severe functional constipation: a pilot randomized double-blind, controlled trial. Tech Coloproctol. 2014;18:945-53.

31. Ding C, Ge X, Zhang X, Tian H, Wang H, Gu L, et al. Efficacy of Synbiotics in Patients with Slow Transit Constipation: A Prospective Randomized Trial. Nutrients. 2016;8:605.

32. Yu T, Zheng YP, Tan JC, Xiong WJ, Wang Y, Lin L. Effects of Prebiotics and Synbiotics on Functional Constipation. Am J Med Sci. 2017;353:282-92.

33. Martínez-Martínez MI, Calabuig-Tolsá R, Cauli O. The effect of probiotics as a treatment for constipation in elderly people: A systematic review. Arch Gerontol Geriatr. 2017;71:142-9.

34. Waitzberg DL, Logullo LC, Bittencourt AF, Torrinhas RS, Shiroma GM, Paulino NP, et al. Effect of synbiotic in constipated adult women - a randomized, double-blind, placebo-controlled study of clinical response. Clin Nutr. 2013;32:27-33.

35. Granata M, Brandi G, Borsari A, Gasbarri R, Gioia DD. Synbiotic yogurt consumption by healthy adults and the elderly: the fate of bifidobacteria and LGG probiotic strain. Int J Food Sci Nutr. 2013;64:162-68.

36. O'Mahony D, O'Leary P, Quigley EM. Aging and intestinal motility: a review of factors that affect intestinal motility in the aged. Drugs Aging. 2002;19:515-27.
37. Macfarlane S, Cleary S, Bahrami B, Reynolds N, Macfarlane GT. Synbiotic consumption changes the metabolism and composition of the gut microbiota in older people and modifies inflammatory processes: a randomised, double-blind, placebo-controlled crossover study. Aliment Pharmacol Ther. 2013;38: 804-16.

38. McLoughlin RF, Berthon BS, Jensen ME, Baines KJ, Wood LG. Short-chain fatty acids, prebiotics, synbiotics, and systemic inflammation: a systematic review and meta-analysis. Am J Clin Nutr. 2017;106:930-45.

39. Vulevic J, Drakoularakou A, Yaqoob P, Tzortzis G, Gibson GR. Modulation of the fecal microflora profile and immune function by a novel trans-galactooligosaccharide mixture (B-GOS) in healthy elderly volunteers. Am J Clin Nutr. 2008;88:1438-46.

40. Eslamparast T, Poustchi H, Zamani F, Sharafkhah M, Malekzadeh R, Hekmatdoost A. Synbiotic supplementation in nonalcoholic fatty liver disease: a randomized, double-blind, placebo-controlled pilot study. Am J Clin Nutr. 2014;99:535-42.

41. Xiao S, Fei N, Pang X, Shen J, Wang L, Zhang B, et al. A gut microbiota-targeted dietary intervention for amelioration of chronic inflammation underlying metabolic syndrome. FEMS Microbiol Ecol. 2014;87:357-67. 